\title{
Sensitivity or censorship?
}

[SF blogs.Ise.ac.uk/polis/2007/04/17/sensitivity-or-censorship/

"If in doubt, don't leave it out" is the motto of a brave broadcaster but sadly, not the BBC's. Their decision to

2007-4-17 cancel the broadcast of a short story by Hanif Kureishi must have been tough. They felt that it would have been insensitive to broadcast this tale of a cameraman in Iraq who films beheadings at a time when BBC correspondent Alan Johnstone is being held hostage in Gaza. I admire the depth of feeling at the BBC about Johnstone's ordeal but I don't believe them when they said that they would have cancelled the broadcast for anyone regardless of whom they worked for.

If they applied that principle consistently to all their output they would never put anything rremotely topical or 'difficult' out at all. The sensible things would have been to have put a 'health warning' before the broadcast or rescheduled it to a later time, perhaps. Why should a fictional short story about a (real) scenario in Iraq really be prevented by a deeply unhappy but isolated incident in the Palestinian territories? This is not censorship. Hanif and other artists who claim some superior political value to the rest of it should get things in perspective. The BBC broadcasts endless indictments of the Iraq War. But he has been mistreated and in this case, I think, the BBC has been self-indulgent in its otherwise commendable concern to avoid hurt and offence.

- Copyright $\odot 2014$ London School of Economics and Political Science 